\title{
Rectal biopsy as a prognostic guide in Crohn's colitis
}

\author{
M. WARD AND J. N. WEBB \\ From the Gastrointestinal Unit, Department of Pathology, Western General Hospital and \\ University of Edinburgh
}

SUMMARY In a retrospective study, 64 rectal biopsies from 27 patients with Crohn's disease limited $\stackrel{\circ}{\circ}$ to the large bowel have been reviewed using a semiquantitative grading of histological abnormality. $\vec{\omega}$ The subsequent clinical course was assessed independently, and patients were included in one of $\frac{\sigma}{\circ}$ four categories: (1) remaining asymptomatic; (2) showing continued moderate inflammatory? activity; (3) requiring colectomy; and (4) dying as a direct result of colonic disease. Biopsies from $\omega$ group (4) showed a greater degree of histological abnormality than those in the other three groups. ? This difference was statistically significant for first rectal biopsies ((4)-(1) P < 0.05; (4)-(2) P $<0.05)$. In any one patient the histological appearances were relatively constant from one biopsy to the $ᄋ$ next. The presence of either fissuring or ulceration suggested a poor prognosis.

A few years after Crohn and his colleagues (1932) described regional ileitis it became apparent that the colon could also be involved by a similar granulomatous inflammation (Colp, 1934; Crohn and Rosenak, 1936). Later studies defined the clinical and pathological feature of granulomatous colitis and dealt with its distinction from ulcerative colitis (Lockhart-Mummery and Morson, 1960 and 1964; Lennard-Jones et al., 1968).

Several recent studies of Crohn's colitis have been concerned with the natural history of the disease after colectomy (Nelson et al., 1973; Korelitz et al., 1972; Nugent et al., 1973) and it has been stated that 'the great majority of the patients with Crohn's disease of the colon will require surgery' (McGovern and Goulston, 1968). Examination of our own cases did not, in fact, confirm this impression of surgical inevitability and revealed a wide spectrum of natural history.

This spectrum extended from a completely asymptomatic course to one which was rapidly downhill and terminated fatally. The present study represents an assessment of the usefulness of rectal biopsy as an indicator of prognosis in Crohn's proctocolitis.

\section{Method}

\section{CLINICAL}

A total of 230 cases of Crohn's disease were traced from the records of this Unit, of which 38 had disease

Received for publication 8 July 1976 limited to the colon. Rectal biopsy material was available for review in 27 of these subjects. Of the $\vec{\perp}$ 11 not studied, two had been lost to follow-up, one 9 had only perianal histology, and eight only operas. ively resected material available for review. All cases studied satisfied the criteria recommended Lennard-Jones (1971) as indicating 'established Crohn's disease'. From the review of the case notes and from current outpatient assessment where $\stackrel{\square}{\mathscr{Q}}$ relevant it was possible to allocate cases into one of $\overrightarrow{\vec{A}}$ four groups of clinical outcome: group 1 (good) $\frac{}{3}$ remaining asymptomatic at latest review with or $כ$ without anti-inflammatory therapy; group 2 (moderate) continued symptomatic activity, either abdominal pain, diarrhoea or rectal blood loss, together? with evidence on sigmoidoscopy of continued $\frac{5}{3}$ inflammation; group 3 (colectomy) disease process of severity sufficient to require colectomy but who $\frac{0}{3}$ subsequently remained in good general health; and group 4 (death) patients who died as a direct result 은 of the severity of the granulomatous colitis. Five of these patients, in fact, died shortly after surgery. The sixth had extensive active fistulating disease $N$ uncontrolled by medical therapy. The clinical details of the subjects studied are shown in Tables 1, 2, and ${ }_{N}$ 3. The clinical classification was made by one of the $\omega$ authors (MW) and was unknown to the other author (JNW) who undertook a review of the histo-o logical material.

\section{Pathological assessment}

All available resected and biopsy material from the 
Table 1 Details of age and sex distribution and length of follow-up in the groups studied

\begin{tabular}{lllll}
\hline & \multicolumn{4}{l}{ Group } \\
\cline { 2 - 5 } & Good & Moderate & Colectomy & Death \\
\hline Number & 7 & 7 & 7 & 6 \\
Male & 5 & 4 & 5 & 1 \\
Age at onset & $34 \cdot 7$ & $22 \cdot 4$ & $39 \cdot 1$ & $38 \cdot 5$ \\
Mean and range (yr) & $(19-68)$ & $(17-36)$ & $(18-49)$ & $(13-62)$ \\
Length of follow-up & $3 \cdot 7$ & $4 \cdot 3$ & $6 \cdot 7$ & $2 \cdot 3$ \\
Mean and range (yr) & $(2-5)$ & $(2-7)$ & $(3-12)$ & $(1-5)$ \\
Onset to surgery & - & - & $2 \cdot 4$ & $1 \cdot 5$ \\
Mean and range (yr) & & & $(0 \cdot 1-8)$ & $(0 \cdot 5-2$ \\
\hline
\end{tabular}

Table 2 Distribution of disease and biopsy frequency

\begin{tabular}{lllll}
\hline & \multicolumn{3}{l}{ Group } & \\
\cline { 2 - 5 } & Good & Moderate & Colectomy & Death \\
\hline Number & 7 & 7 & 7 & 6 \\
Distribution & 4 & 2 & 4 & 3 \\
$\quad$ left-sided & 2 & 0 & 1 & 0 \\
$\quad$ right-sided & 1 & 4 & 1 & 2 \\
$\quad$ total & 0 & 1 & 1 & 1 \\
$\quad$ segmental & 3 & 6 & 5 & 3 \\
Perianal disease & 2 & 3 & 2 & 1 \\
Biopsy frequency & 1 & 2 & 2 & 2 \\
$\times 1$ & 2 & 2 & 2 & 1 \\
$\times 2$ & 2 & 0 & 1 & 2 \\
$\times 3$ & 18 & 13 & 16 & 16 \\
$\quad \times 4$ & $2 \cdot 6$ & $1 \cdot 9$ & $2 \cdot 3$ & $2 \cdot 7$ \\
Total no. biopsies & & & \\
Mean biopsy frequency & $2 \cdot 6$ & & & \\
\hline
\end{tabular}

27 subjects was reviewed, and this report deals with the rectal biopsies. Of 64 rectal biopsies available, 25 had originally been considered as being diagnostic of Crohn's disease. In those cases which did not have this diagnostic histology in the rectal biopsy, the histological diagnosis had been made from either resected large bowel or anal or perianal biopsies. All 64 biopsies were reviewed whether or not they had originally shown the typical appearances of Crohn's disease.
Ten histological features were studied (Table 4). These features were divided into two groups, as shown in the Table: first, those which could be said to be either present or absent, such as ulceration or fissures; and, secondly, those which could be graded on a semiquantitative scale, such as mucin depletion or infiltration by neutrophils or plasma cells. An arbitrary scoring system was derived, as shown in Table 4, and it was therefore possible to obtain a score for each individual biopsy and also to analyse the pattern of individual histological features within the four clinical groups studied. It may thus be seen that if all the non-graded features were to be present in one biopsy together with all the graded features in their most severe form, then a total score derived for that biopsy would be 10 points. For analysis of individual histological features, the total number of points attributable to each feature in the four clinical groups were added together and the result was expressed as a percentage of the theoretical maximum possible score for that histological feature in the clinical group under consideration. For the nongraded features this percentage therefore represents a simple frequency of appearance of the histological feature, whereas for the graded features it represents a combination of frequency of appearance and severity. Because it is possible that treatment might influence appearance of the biopsy, the first rectal biopsy was considered as a separate group for comparative purposes. With regard to treatment, seven of the 27 'first' rectal biopsies were from subjects who were receiving anti-inflammatory drugs at the time whereas the majority of subsequent rectal biopsies were taken during therapy with such drugs. The second reason for considering the first biopsy as a separate group was that the different clinical course in the four groups might have resulted in a different use of investigation of rectal biopsy. In fact

Table 3 Details of surgery and subsequent course in the 'colectomy' and 'death' groups

\begin{tabular}{|c|c|c|c|c|}
\hline Group & Case & Indication for surgery & Type of operation & Subsequent course \\
\hline Colectomy & $\begin{array}{l}1 \\
2 \\
3 \\
4 \\
5 \\
6 \\
7\end{array}$ & $\begin{array}{l}\text { Severe perianal disease } \\
\text { Severe perianal disease } \\
\text { Failed medical therapy } \\
\text { Failed medical therapy } \\
\text { Obstruction due to stricture } \\
\text { Acute colonic haemorrhage } \\
\text { Toxic dilatation }\end{array}$ & $\begin{array}{l}\text { TPC } \\
\text { TPC } \\
\text { TPC } \\
\text { TPC } \\
\text { STC + IRA } \\
\text { STC + RR } \\
\text { STC + RR }\end{array}$ & $\begin{array}{l}\text { Asymptomatic } \\
\text { Asymptomatic } \\
\text { Asymptomatic } \\
\text { Asymptomatic } \\
\text { Asymptomatic } \\
\text { Asymptomatic } \\
\text { Recent drainage abdominal abscess; good } \\
\text { general health }\end{array}$ \\
\hline Death & $\begin{array}{l}1 \\
2 \\
3 \\
4 \\
5 \\
5\end{array}$ & $\begin{array}{l}\text { Failed medical therapy } \\
\text { Failed medical therapy } \\
\text { Failed medical therapy } \\
\text { Failed medical therapy } \\
\text { Obstruction due to stricture } \\
\text { No surgery }\end{array}$ & $\begin{array}{l}\text { STC + RR } \\
\text { TPC } \\
\text { TPC } \\
\text { RHC + RR } \\
\text { ITC } \\
-\end{array}$ & $\begin{array}{l}\text { Postoperative sepsis; died } \\
\text { Postoperative sepsis; died } \\
\text { Postoperative sepsis; died } \\
\text { Subsequent small bowel disease } \rightarrow \\
\text { perforation } \rightarrow \text { postoperative sepsis; died } \\
\text { Postoperative sepsis; died } \\
\text { Uncontrolled disease with multiple fistulae }\end{array}$ \\
\hline
\end{tabular}

$\overline{\mathrm{TPC}}=$ total proctocolectomy; $\mathbf{S T C}=$ subtotal colectomy; IRA $=$ ileorectal anastomosis; $\mathbf{R R}=$ resection of rectum; $\mathbf{R H C}=$ right hemicolectomy; ITC = ileotransverse colostomy 
Table 4 Details of histological scoring system

\begin{tabular}{|c|c|c|c|c|c|c|c|}
\hline \multirow[t]{3}{*}{ Feature } & \multirow{2}{*}{\multicolumn{2}{|c|}{$\begin{array}{l}\text { Non-graded } \\
\text { Score }\end{array}$}} & & \multicolumn{4}{|l|}{ Graded } \\
\hline & & & & \multicolumn{4}{|l|}{ Score } \\
\hline & 0 & 1 & & 0 & $1 / 3$ & $2 / 3$ & 1 \\
\hline $\begin{array}{l}\text { Ulceration } \\
\text { Fissure } \\
\text { Crypt abscess } \\
\text { Oedema } \\
\text { Granuloma }\end{array}$ & $\begin{array}{l}\text { Absent } \\
\text { Absent } \\
\text { Absent } \\
\text { Absent } \\
\text { Absent }\end{array}$ & $\begin{array}{l}\text { Present } \\
\text { Present } \\
\text { Present } \\
\text { Present } \\
\text { Present }\end{array}$ & $\begin{array}{l}\text { Mucin depletion } \\
\text { Gland irregularity } \\
\text { Lymphoid hyperplasia } \\
\text { Neutrophil infiltration } \\
\text { Plasma-cell infiltration }\end{array}$ & $\begin{array}{l}\text { Nil } \\
\text { Nil } \\
\text { Nil } \\
\text { Nil } \\
\text { Normal }\end{array}$ & $\begin{array}{l}\text { Slight } \\
\text { Slight } \\
\text { Slight } \\
\text { Slight } \\
\text { Excess upper third } \\
\text { mucosa only }\end{array}$ & $\begin{array}{l}\text { Moderate } \\
\text { Moderate } \\
\text { Moderate } \\
\text { Many foci } \\
\text { Moderate throughout } \\
\text { mucosa }\end{array}$ & $\begin{array}{l}\text { Marked } \\
\text { Marked } \\
\text { Marked } \\
\text { Diffuse and heavy } \\
\text { Heavy throughout } \\
\text { mucosa }\end{array}$ \\
\hline
\end{tabular}

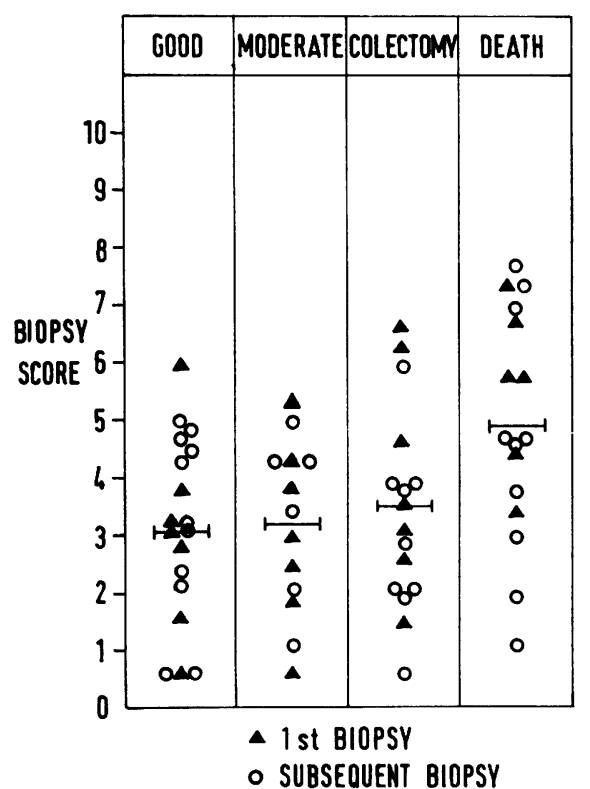

Fig 1 Score of individual rectal biopsies in the four clinical groups studied. Horizontal bar = mean of group.

there was no statistically significant difference in the biopsy frequency in the four groups (Table 2).

\section{Results}

\section{SCORES IN INDIVIDUAL BIOPSIES}

Figure 1 shows the score of individual biopsies in each of the four groups for both first and subsequent biopsies. As may be seen from this figure, there was considerable overlap among the four groups. However, the use of Student's $t$ test applied to first rectal biopsies showed a significant difference between scores of the death group and the moderate group $(P<0.05)$ and between the death group and the good group $(P<0.05)$. As most patients contributed more than one biopsy to the study statistical comparison of all biopsies in each group is not valid, but examination of Fig. 1 shows that the score of subsequent biopsies was similar to that of the first biopsy. The relationship of scores of first and second? biopsies in the 19 subjects in whom more than one $O$ rectal biopsy had been performed was examined and? a significant correlation was found $(R=0.59, \vec{N}$ $P<0.01$ ).

INDIVIDUAL HISTOLOGICAL FEATURES Figure 2 shows the frequency of non-graded features $\frac{D}{O}$ in each clinical group for both first and subsequent rectal biopsies. The most striking finding in this respect was that in no biopsy, either first or subse- $\vec{\theta}$ quent from patients in the good or moderate groug, was a fissure found whereas these were present $\mathrm{g}$. between $30 \%$ and $50 \%$ of the biopsies in the other two groups. Also, ulcers were not seen in any of the first rectal biopsies of those in the good group and only rarely in subsequent biopsies in this group, 응 whereas they were relatively common in all of the other three groups. Another interesting finding was $\overrightarrow{\hat{O}}$ that granulomata were relatively common in the 3 biopsies of those patients who subsequently did well or, on the other hand, who subsequently died as a result of their disease whereas they were $a \overline{0}$ relatively uncommon finding in the other two groups.

Figure 3 shows a similar scheme for comparison 3 . of the graded features. As may be seen, no very' striking differences emerged except that there was a tendency for first biopsies from the groups with the worst prognosis to show greater degrees of neutrophil and plasma cell infiltration when compared with those with the better prognosis.

\section{Discussion}

The rectal biopsy represents only a small sample ${ }_{\sigma}^{\omega}$ from the whole large bowel, and Crohn's disease is well known for its patchy distribution. Nevertheless? this study shows that there are certain histological features in rectal tissue which give an indication of the eventual clinical outcome. Thus, with the $10 \bar{\circ}$ histological features studied and considered together $\vec{D}$ for each biopsy, there was an increase in the degree $\frac{}{D}$ 


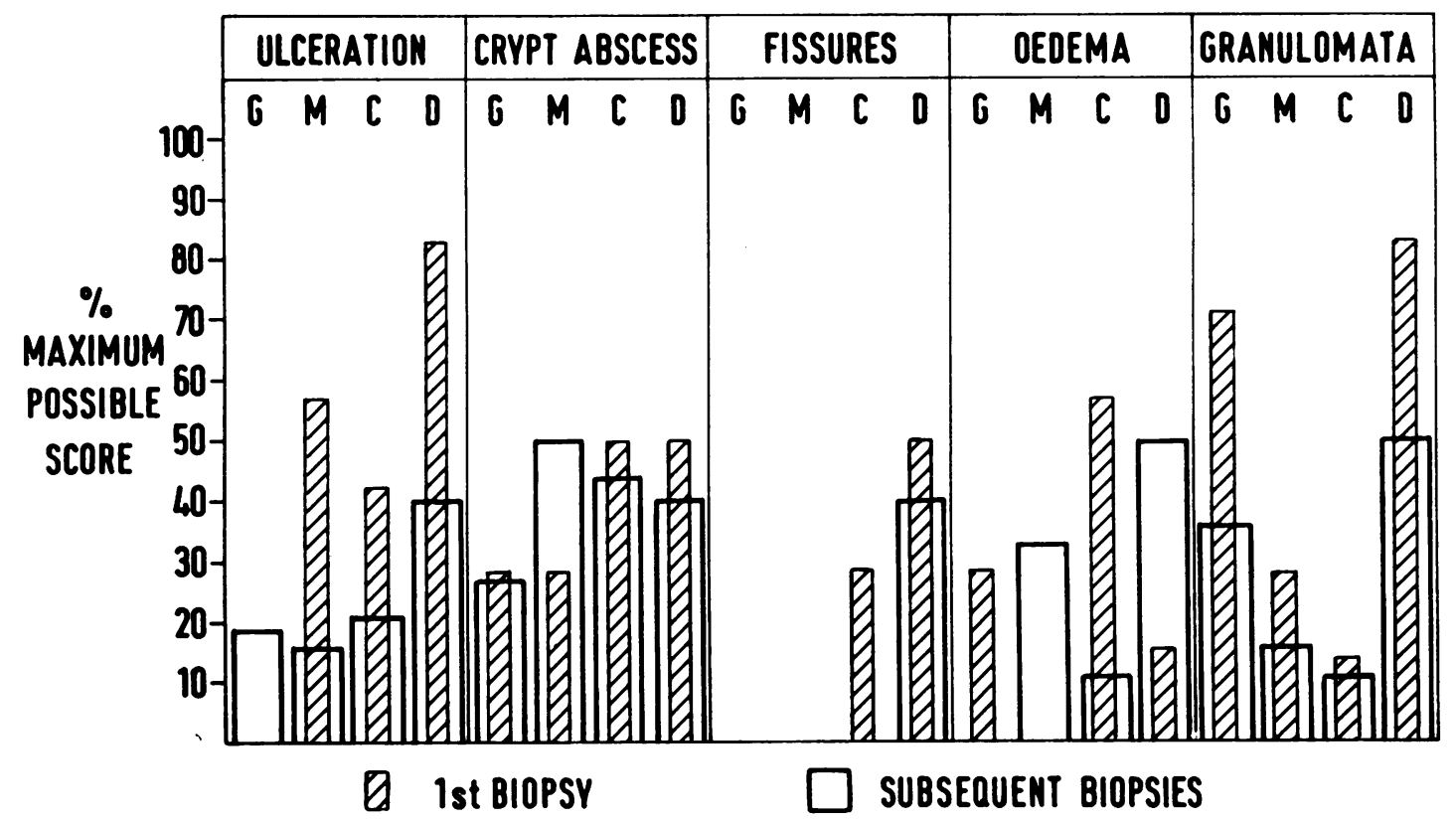

Fig 2 Frequency score for non-graded individual histological features of first and subsequent biopsies; $G=$ good: $M=$ moderate: $C=$ colectomy: $D=$ death.

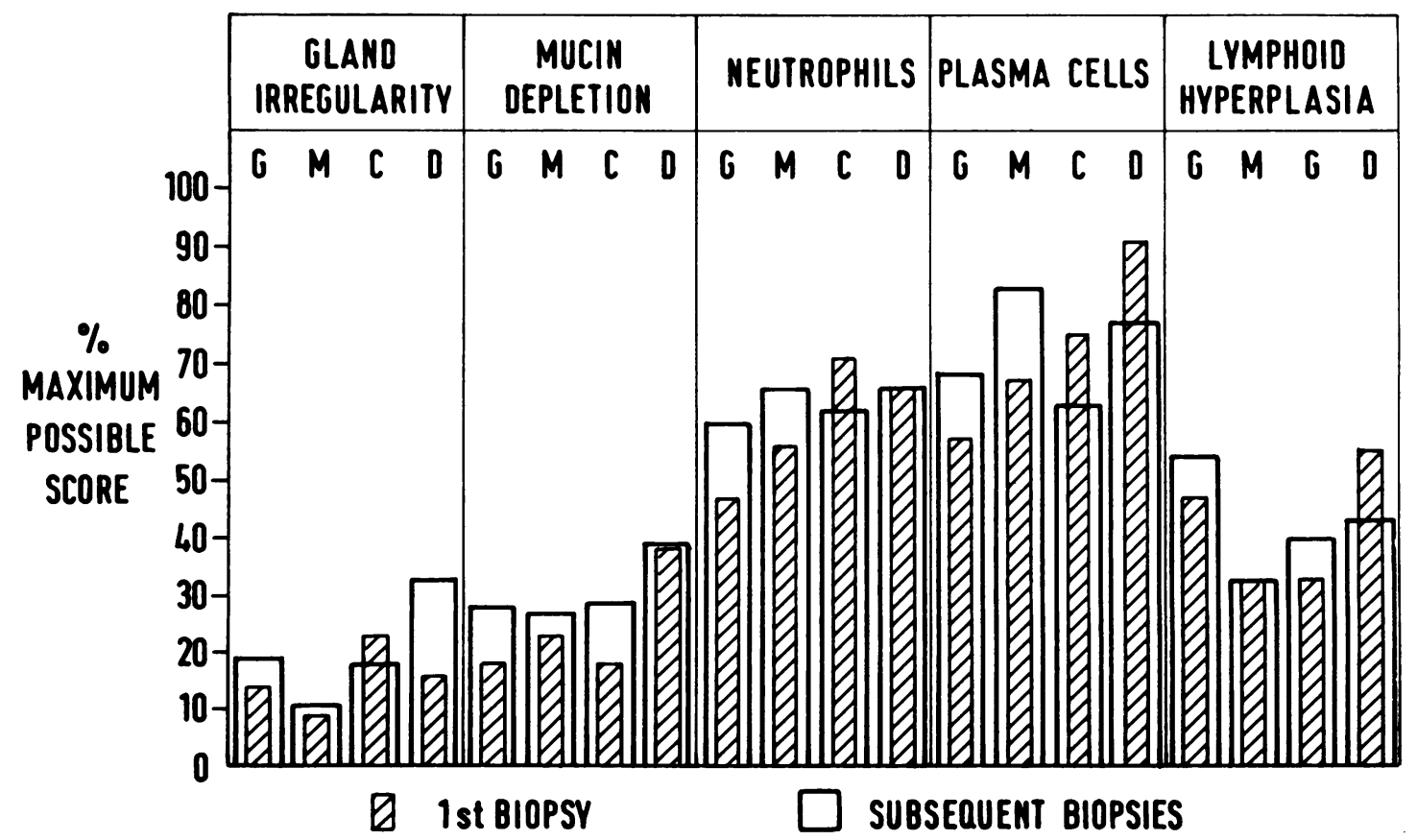

Fig 3 Frequency-severity score for graded individual histological features for first and subsequent biopsies. 
of histological abnormality in biopsies of patients who subsequently died of granulomatous colitis or its complications when compared with those with a good prognosis or those who showed only moderate inflammatory activity while under a medical regime of treatment. These differences are statistically significant for the first rectal biopsy. A similar pattern of abnormality was seen on subsequent biopsies and did not appear to be due to greater frequency of biopsy nor to a greater proportion of patients with either more distal or more extensive involvement of the colon or with perianal disease in those with a poor prognosis (Table 2). Although the numbers involved are too small for definite conclusions to be drawn, it is of interest that five of the six patients who died from granulomatous colitis were female, and five of the same group also died in the immediate postoperative period. In studies such as this it is obviously important to consider also the total length of follow-up in each of the groups to ensure that those with an apparently good prognosis are not simply being followed up for a shorter period of time. In fact, with the four groups used in the present study the relevant interval is obviously that between onset of disease and death in the group with the fatal outcome. As may be seen from Table 1, both of these intervals are shorter than the total length of follow-up in the good and moderate groups.

Of the individual histological features, ulceration and fissures seem to be particularly bad prognostic signs which were not simply related to the presence of distal colonic involvement or perianal disease. The occurrence of fissuring as a bad prognostic sign is perhaps not altogether surprising as obviously the fissure is likely to be the point of origin of a fistula which will increase the risk of surgical morbidity and mortality.

Most studies of Crohn's disease have attempted to correlate histology with clinical features of utilised resected small bowel and have not found a good correlation (Van Patter et al., 1954; Antonius et al., 1960). An exception to these generally negative findings was the study of Kawel and Tesluk (1955) which did show that the presence of Brunner-type glands development in resected ileum was associated with a high subsequent recurrence rate. Another study of operatively resected material from patients with ileocolitis failed to identify any histological feature which related to subsequent clinical recurrence but did show that initial extensive involvement of the gut and perianal disease indicated a high risk of recurrence (Gump et al., 1972). The rectal biopsy has also been studied in Crohn's disease by Anderson and Bogoch (1968), who found non-specific inflammatory changes in $43 \%$ of rectal biopsies from 30 patients with small bowel involvement but found no correlation of clinical activity. Dyer et al. (1970) reported similar findings in the rectal biopsies of $\%$ patients with small bowel disease and a higher $\overrightarrow{\vec{A}}$ incidence of histological abnormality $(73 \%)$ in patients with large bowel Crohn's disease. These authors also found no association between biopsy $\frac{\bar{\sigma}}{\bar{c}}$. appearances and duration of symptoms or disease $\vec{\nabla}$ activity. These studies have been concerned with $\varrho$ clinical features existing at the time of biopsy $\%$ whereas the present study related biopsy appearance $\overrightarrow{0}$ to subsequent clinical outcome over a number of $\overrightarrow{ }$ years.

It is known that in certain diseases where there are aberrations of immunity, such as Hodgkins disease? (Cross, 1969), leprosy (Ridley and Jopling, 1966), w and rheumatoid arthritis (Muirden and Mills, 1971), ? lymphocyte depletion in the tissues tends to be $\vec{N}$

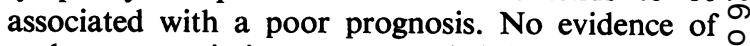
such an association was revealed by the present study. However, the methods of assessing the degree $\vec{T}$ of lymphocyte infiltration used were relatively crude $\mathbb{D}$ and it is possible that more subtle techniques which have been reported in other circumstances (Binder, 离 1970; Ferguson and Murray, 1971) might be more rewarding. The high incidence of crypt abscesses (approximately $40 \%$ overall) in this study serves to underline the fact that this feature, although found much more commonly in ulcerative colitis, is by no means restricted to this condition, as has been pointed out by other authors (Lennard-Jones et al., 1968). Dyer et al. (1970) found crypt abscesses in only $7 \%$ of their series of 97 rectal biopsies in Crohn's disease. This low figure probably reflects the fact that these authors were studying both small and large bowel disease whereas the present study was limited to large bowel disease alone. The incidence of granulomata in the rectal biopsy of patients with Crohn's disease is reported to be around $20 \%$ (Cornes and Stecher, 1961; Dyer et al., 1970). The overall incidence in the present series was $39 \%$. Again this higher figure probably reflects the fact that only cases of large bowel disease were being studied. This finding of an increased incidence of granulomata is more in keeping with other reports such as that of Lockhart-Mummery and Morson (1964), who found granulomata in 16 of 19 biopsies performed in a series of 75 cases of Crohn's disease of the colon. The reason for the rather curious distribution of granulomata, in that they occurred in the group which either did well or died from the disease, with relatively few granulomata in the other two groups, is not clear. It may simply be a sampling artefact that in these two groups (moderate and colectomy) granulomata were, in fact, frequently found in either the resected colon of the colectomy 
group or in skin tags or perianal tissue in the moderate group. It is of interest, however, that a recent study of operatively resected material reports a better prognosis for those cases in which granulomata were present than for those without this feature (Glass and Baker, 1976).

The results of the present study suggest that there are features to be found in the rectal biopsies of patients with Crohn's colitis which give some indication of the ultimate prognosis, and that biopsy appearances are relatively constant. Ulceration and fissuring seem to be particularly bad prognostic signs.

The scoring system used in this study is arbitrary and introduces a weighting of unknown importance. Also, because the numbers involved are small the findings can be said only to indicate trends. These small numbers are a reflection of the low incidence in any one centre of Crohn's disease limited to the colon. To overcome this difficulty a collaboration prospective study might establish the exact value of rectal biopsy as a prognostic indicator. Alternatively, the extension of the study to include cases where both small and large bowel are involved should provide sufficient material to allow the development of a most sophisticated histological and statistical analysis.

We are grateful for the helpful criticism and advice of Dr Anne Ferguson and for permission to study patients under the care of Drs W. Sircus, M. A. Eastwood, and J. P. McManus.

\section{References}

Anderson, F. H. and Bogoch, A. (1968). Biopsies of large bowel in regional enteritis. Canadian Medical Association Journal, 98, 150-153.

Antonius, J. I., Gump, F. E., Lattes, R., and Lepore, M. (1960). A study of certain microscopic features in regional enteritis, and their possible prognostic significance. Gastroenterology, 38, 889-905.

Binder, V. (1970). Cell density in lamina propria of the colon: a quantitative method applied to normal subjects and ulcerative colitis patients. Scandinavian Journal of Gastroenterology, 5, 485-490.

Colp, R. (1934). A case of nonspecific granuloma of the terminal ileum and the cecum. Surgical Clinics of North America, 14, 443-449.

Cornes, J. S. and Stecher, M. (1961). Primary Crohn's disease of the colon and rectum. Gut, 2, 189-201.

Crohn, B. B., Ginzburg, L., and Oppenheimer, G. D. (1932). Regional ileitis-a pathologic and clinical entity. Journal of American Medical Association, 99, 1323-1329.

Crohn, B. B. and Rosenak, B. D. (1936). A combined form of ileitis and colitis. Journal of American Medical
Association, 106, 1-7.

Cross, R. M. (1969). Hodgkin's disease: histological classification and diagnosis. Journal of Clinical Pathology, 22, 165-182.

Dyer, N. H., Stansfeld, A. G., and Dawson, A. M. (1970). The value of rectal biopsy in the diagnosis of Crohn's disease. Scandinavian Journal of Gastroenterology, 5, 491-496.

Ferguson, A. and Murray, D. (1971). Quantitation of intraepithelial lymphocytes in human jejunum. Gut, 12, 988-994.

Glass, R. E. and Baker, W. N. W. (1976). Role of the granuloma in recurrent Crohn's disease. Gut, 17, 75-77.

Gump, F. E., Sakellariadis, P., Wolff, M., and Broell, J. R. (1972). Clinical-pathological investigation of regional enteritis as a guide to prognosis. Annals of Surgery, 176, 233-242.

Kawel, C. A., Jr. and Tesluk, H. (1955). Brunner-type glands in regional enteritis. Gastroenterology, 28, 810-820.

Korelitz, B. I., Present, D. H., Alpert, L. I., Marshak, R. H., and Janowitz, H. D. (1972). Recurrent regional ileitis after ileostomy and colectomy for granulomatous colitis. New England Journal of Medicine, 287, 110-115.

Lennard-Jones, J. E. (1971). Definition and diagnosis. In Regional Enteritis (Crohn's Disease); Skandia International Symposia, Vol. V, edited by A. Engel and T. Larsson, pp. 105-112. Nordiska Bokhandelns Förlag, Stockholm.

Lennard-Jones, J. E., Lockhart-Mummery, H. E., and Morson, B. C. (1968). Clinical and pathological differentiation of Crohn's disease and proctocolitis. Gastroenterology, 54, 1162-1170.

Lockhart-Mummery, H. E. and Morson, B. C. (1960). Crohn's disease (regional enteritis) of the large intestine and its distinction from ulcerative colitis. Gut, 1, 87-105.

Lockhart-Mummery, H. E. and Morson, B. C. (1964). Crohn's disease of the large intestine. Gut, 5, 493-509.

McGovern, V. J. and Goulston, S. J. M. (1968). Crohn's disease of the colon. Gut, 9, 164-176.

Muirden, K. D. and Mills, K. W. (1971). Do lymphocytes protect the rheumatoid joint? British Medical Journal, 4, 219-221.

Nelson, J. A., Margulis, A. R., Goldberg, H. I., and Lawson, T. L. (1973). Granulomatous colitissignificance of involvement of the terminal ileum. Gastroenterology, 64, 1071-1076.

Nugent, F. W., Veidenheimer, M. C., Meissner, W. A., and Haggitt, R. C. (1973). Prognosis after colonic resection for Crohn's disease of the colon. Gastroenterology, 65, 398-402.

Ridley, D. S. and Jopling, W. H. (1966). Classification of leprosy according to immunity-a five group system. International Journal of Leprosy, 34, 255-273.

Van Patter, W. N., Bargen, J. A., Dockerty, M. B., Feldman, W. H., Mayo, C. W., and Waugh, J. M. (1954). Regional enteritis. Gastroenterology, 26, 347-450. 